\title{
Different effects of soluble and aggregated amyloid 42 on gene/protein expression and enzyme activity involved in insulin and APP pathways
}

\author{
Bartl, Jasmin ; Meyer, Andrea ; Brendler, Svenja ; Riederer, Peter ; Grünblatt, Edna
}

\begin{abstract}
Although Alzheimer's dementia (AD) is not characterised any longer simply as the accumulation and deposition of amyloid beta (A ) peptides and hyperphosphorylation of tau proteins within the brain, excessive A (42) deposition is still considered to play a major role in this illness. A are able to adopt many differently aggregate forms, including amyloid fibrils as well as nonfibrillar structures (soluble A (42) oligomers). It is not well-established that which A (42) state is most responsible for AD or why. We wanted to verify which effects A (42) oligomers and aggregated peptides have on gene expression, protein level and enzyme activity of insulin and amyloid precursor protein (APP) pathways in vitro. Human neuroblastoma cells (SH-SY5Y) were treated with varying concentrations of soluble and aggregated A (42). Treatment effects on -secretase (BACE), glycogen synthase kinase 3 (GSK3), glycogen synthase kinase 3 (GSK3 ), phosphatidylinositol-3 kinase (PI-3K), insulin-degrading enzyme (IDE), insulin-receptor substrate 1 (IRS1), insulin receptor (INSR) and monoamine oxidase B (MAO-B) were investigated via quantitative-PCR, western blot, ELISA and enzyme activity assay. We could find different effects of soluble and aggregated peptides especially on gene/protein expression of GSK3 and INSR and on GSK3 and MAO-B activity. Soluble peptides showed significant effects leading to increased gene expression and protein amount of GSK3 and to decreased level of gene and protein expression of INSR. MAO-B activity was enhanced after treatment with aggregated peptides and strongly inhibited after soluble A (42) treatment. Our data might provide insights into selective effects of specific forms of $\mathrm{A}(42)$ aggregates in $\mathrm{AD}$.
\end{abstract}

DOI: https://doi.org/10.1007/s00702-012-0852-5

Posted at the Zurich Open Repository and Archive, University of Zurich

ZORA URL: https://doi.org/10.5167/uzh-74502

Journal Article

Accepted Version

Originally published at:

Bartl, Jasmin; Meyer, Andrea; Brendler, Svenja; Riederer, Peter; Grünblatt, Edna (2013). Different effects of soluble and aggregated amyloid 42 on gene/protein expression and enzyme activity involved in insulin and APP pathways. Journal of Neural Transmission, 120(1):113-120.

DOI: https://doi.org/10.1007/s00702-012-0852-5 
Different effects of soluble and aggregated Amyloid $\beta_{42}$ on gene/ protein expression and enzyme activity involved in insulin and APP pathways

Jasmin Bartl $^{1 \bowtie}$, Andrea Meyer ${ }^{1}$, Svenja Brendler ${ }^{1}$, Peter Riederer ${ }^{1}$, Edna Grünblatt ${ }^{1,2}$

${ }^{1}$ Department of Psychiatry, Psychosomatics and Psychotherapy, University Hospital of Wuerzburg, Wuerzburg, Germany,

${ }^{2}$ Hospital of Child and Adolescent Psychiatry, University of Zurich, Zurich, Switzerland

Pages: 14; Abstract: 248 words; Main text: 2998 words; Tables: 1; Figures: 3; Supplementary material: 2 ;

All correspondence to Dipl- biol. Jasmin Bartl:

Department of Psychiatry, Psychosomatics and Psychotherapy, University Hospital of Wuerzburg, Wuerzburg, Germany,

Tel: +49-(0)931-20177300; Fax: +49-(0)931-20177232; E-mail: e bartl j@klinik.uni-wuerzburg.de

Key words: Alzheimer's dementia, soluble/aggregated A $\beta_{42}$, GSK3 $\beta$, insulin receptor, MAO-B 


\section{Abstract}

Although Alzheimer's dementia (AD) is not anymore characterised just by the accumulation and deposition of amyloid beta $(\mathrm{A} \beta)$ peptides and hyperphosphorylation of tau proteins within the brain, excessive $A \beta_{42}$ deposition is still considered to play a major role in $A D$. $A \beta$ are able to adopt many differently aggregate forms, including amyloid fibrils as well as nonfibrillar structures (soluble $\mathrm{A} \beta_{42}$ oligomers). It is not well established which $\mathrm{A} \beta_{42}$ state is most responsible for $\mathrm{AD}$ or why. We wanted to verify, which effects $A \beta_{42}$ oligomers and aggregated peptides have on gene expression, protein level and enzyme activity of insulin and amyloid precursor protein (APP) pathways in vitro. Human neuroblastoma cells (SH-SY5Y) were treated with varying concentrations of soluble and aggregated $\mathrm{A} \beta_{42}$. Treatment effects on $\beta$-secretase (BACE), glycogen synthase kinase $3 \alpha$ (GSK3 $\alpha$ ), glycogen synthase kinase $3 \beta$ (GSK3 $\beta$ ), phosphatidylinisitol-3 kinase (PI-3K), insulin degrading enzyme (IDE), insulin receptor substrate 1 (IRS1), insulin receptor (INSR) and monoamine oxidase B (MAO-B) was investigated via quantitative-PCR, western blot, ELISA and enzyme activity assay. We could find different effects of soluble and aggregated peptides especially on gene/ protein expression of GSK3 $\beta$ and INSR and on GSK3 $\beta$ and MAO-B activity. Soluble peptides showed significant effects leading to increased gene expression and protein amount of GSK3 $\beta$ and to decreased level of gene and protein expression of INSR. MAO-B activity was enhanced after treatment with aggregated peptides and strongly inhibited after soluble $A \beta_{42}$ treatment. Our data might provide insights into selective effects of specific forms of $A \beta_{42}$ aggregates in $\mathrm{AD}$. 


\section{Introduction}

Alzheimer's dementia (AD) is not anymore characterised just by the accumulation and deposition of amyloid beta $(\mathrm{A} \beta)$ peptides and hyperphosphorylated tau proteins within the brain; in the mean time, it is also characterised by synaptic loss (Small, 2004), imbalanced metabolism (Schindowski et al., 2008; Grünblatt et al., 2010), abnormal protein cross-linking (Munch et al., 1998; Wang et al., 2008), and disturbance of the insulin signalling pathway (Hoyer et al., 1994; de la Monte et al., 2009; Riederer et al., 2010). Although more and more factors are found to be involved in $A D$, excessive $A \beta_{42}$ deposition is still considered to play a major role in $\mathrm{AD}$. However, the mechanisms that contribute to abnormal $\mathrm{A} \beta_{42}$ accumulation are not fully understood, both increased production and decreased degradation have been observed (Crouch et al., 2008). $\mathrm{A} \beta_{42}$ are able to adopt many differently shaped aggregates including amyloid fibrils (Glabe, 2008) as well as nonfibrillar aggregates that are also termed soluble $\mathrm{A} \beta_{42}$ "oligomers"(Haass and Selkoe, 2007). It is not well established which $A \beta$ state is most responsible for $\mathrm{AD}$ or why. Recent evidence strongly implicates $A \beta_{42}$ oligomers as the proximal pathogenic trigger (De Felice et al., 2008). These oligomers are markedly elevated in the brain and cerebrospinal fluid of postmortem $\mathrm{AD}$ patients and appear to play a critical role in the synaptic failure and memory deficits of early AD (Klyubin et al., 2008). It is therefore important to determine directly whether neurons exposed to oligomers undergo pathological changes characteristic of AD brain. In the current study, we sought to verify the effects of both oligomers and aggregated $A \beta_{42}$ peptides on gene expression, protein level and enzyme activity in vitro. The cell culture model chosen for this investigation was the human SH-SY5Y neuroblastoma cell line. These cells show the most common neurobiochemical (e.g. enzymes like dopamine $\beta$-hydroxylase, acetylcholintransferase, etc. and neurotransmitter like dopamine, adrenaline, acetylcholine, GABA) and neurobiological factors (e.g. dopamine transporter and receptors, GABAergic receptors, etc.) (Biedler et al., 1978; Ross et al., 1983) and can be perfectly used as an experimental model to study effects of $A \beta_{42}$ oligomers and aggregated $A \beta_{42}$ peptides. Our main focus lay on treatment effects on $\beta$-secretase (BACE), glycogen synthase kinase $3 \alpha$ (GSK3 $\alpha$ ), glycogen synthase kinase $3 \beta$ (GSK3 $\beta$ ), phosphatidylinisitol-3 kinase (PI-3K), insulin degrading enzyme (IDE), insulin receptor substrate 1 (IRS1), insulin receptor (INSR) and monoamine oxidase B (MAO-B). They are all already known to be involved in the pathology of 
$\mathrm{AD}$ : $\mathrm{BACE}$ is the first protease in the processing of amyloid precursor protein (APP) leading to the production of $A \beta_{42}$ in the brain, therefore it is one recent target for therapeutic treatment of $\mathrm{AD}$ (Ghosh et al., 2011). Over-activity of GSK3 accounts for memory impairment, tau hyperphosphorylation, increased $\mathrm{A} \beta$ production and local plaque-associated microglial-mediated inflammatory responses; all of which are hallmark characteristics of AD (reviewed in (Hooper et al., 2008)). PI-3K has been identified as second messenger system providing anti-apoptotic signal to various cell types (Brunet et al., 2001). Additionally, neuroprotection against extracellular $A \beta_{42}$ toxicity is dependent on PI-3K pathway (Zhang et al., 2003; Lesne et al., 2005). IDE is a metalloprotease that apart from insulin also binds and degrades other substrates, including $A \beta_{42}$, therefore reduced IDE activity diminishes $A \beta$ clearance and contributes to the formation of senile plaques (Mukherjee et al., 2000). Not only for IDE insulin and $A \beta_{42}$ are counterparts, in fact $A \beta_{42}$ peptides directly compete with insulin for binding to the INSR (de la Monte et al., 2009) and INSR dysfunction impairs cellular clearance of neurotoxic oligomeric $A \beta_{42}$ (Zhao et al., 2009). MAO-B activity is significantly increased in AD patients (Gotz et al., 1998; Grünblatt et al., 2005) and inhibition of MAO-B has a neuroprotective effects for AD (reviewed in (Riederer et al., 2004).

\section{Material and Methods}

\section{Cell culture}

SH-SY5Y cells were bought from European Collection of Cell Cultures and grown in buffered Dulbecco`s modified Eagle medium (DMEM/F-12) (Pan Biotech GmbH, Aidenbach, Germany) supplemented with $10 \%$ fetal bovine serum and $0.1 \%$ gentamycin $(50 \mathrm{mg} / \mathrm{ml})$ (Life technologies, Darmstadt, Germany) in a humidified incubator $\left(5 \% \mathrm{CO}_{2}\right)$ at $37^{\circ} \mathrm{C}$.

\section{Preparation of soluble and aggregated $A \beta_{42}$}

The preparation of the $A \beta_{42}$ peptide was modified according to Dahlgren (Dahlgren et al., 2002). $500 \mathrm{mg}$ of freeze-dried $\mathrm{A} \beta_{42}$ (Millipore, Schwalbach, Germany) was dissolved in 1,1,1,3,3,3 hexafluoroisopropanol (HFIP) to a concentration of $1 \mathrm{mM}$ and incubated for one hour at room temperature. Subsequently, the HFIP was removed by using a vacuum centrifuge and the peptide film 
was dissolved in dry dimethyl sulfoxide (DMSO) to a final concentration of 5mM. For aggregated $\mathrm{A} \beta_{42}$ peptides, the solution was diluted with $10 \mathrm{mM} \mathrm{HCl}$ and stored for 7 days in the incubator at $37^{\circ} \mathrm{C}$. The test concentrations of both the soluble and the aggregated $A \beta_{42}$ were finally diluted with normal cell culture medium.

\section{Cell treatment with $A \beta_{42}$}

For western blot (WB), enzyme linked immunosorbent assay (ELISA), fluorescent ELISA and quantitative real-time polymerase chain reaction (QRT-PCR), SH-SY5Y cells were treated with varying concentrations of soluble and aggregated $\mathrm{A} \beta_{42}$ (see preparation above) $(0,5,1,2,5$ and $10 \mu \mathrm{M})$, or purified DMSO or $\mathrm{HCl}$ as a control, by adding it in the right concentration to the culture medium. The reaction was stopped after $48 \mathrm{~h}$ and cells were trypsinized for further investigations.

\section{Cytotoxicity}

To determine a possible toxic effect of $\mathrm{A} \beta_{42}$ on the cells, the CytoTox-Glo ${ }^{\mathrm{TM}}$ test from Promega (Mannheim, Germany) was performed. For testing the cytotoxicity effect, 10.000 cells/ml per well were cultivated for 24 hours at $37^{\circ} \mathrm{C}$ in $5 \% \mathrm{CO}_{2}$ saturation in the incubator, so that the cells could adhere to the bottom of the wells. Afterwards cells were treated with soluble or aggregated $A \beta_{42}$ in a concentration of $0.1,0.5,1,2,3,5,10,20,50$ and $100 \mu \mathrm{M}$. Reaction was measured $48 \mathrm{~h}$ later.

\section{RNA extraction and $Q R T-P C R$}

Total RNA was extracted from SH-SY5Y cells using the RNeasy Plus MiniKit (Qiagen, Hilden, Germany) according to the manufacturer's instructions. Total RNA (500 ng) was reverse transcribed using the iScript cDNA Synthesis Kit (Bio-Rad Laboratories, Munich, Germany). QRT-PCR was performed using an iCycler $\mathrm{iQ}^{\mathrm{TM}}$ Real Time PCR Detection System (Bio-Rad) and the SYBR-Green detection method. The QRT-PCR reaction was optimized according to the manufacturer's instructions. QuantiTech Primer assays for $\beta$-actin (ACTB; QT00193473), glyceraldehyde-3-phosphate dehdrogenase (GAPDH, QT01192646), ribosomal protein L13A (RPL13A; QT00089915), peptidylprolyl isomerase A (PPIA, QT01866137), $\beta$-secretase (BACE, QT00084777), glycogen synthase kinase $3 \alpha$ (GSK3 $\alpha$, QT00075306), glycogen synthase kinase $3 \beta$ (GSK3 $\beta$, QT00057134), phosphatidylinisitol-3 
kinase (PI-3K, QT00035175), insulin degrading enzyme (IDE, QT00080773), insulin receptor substrate 1 (IRS1, QT00074144) and insulin receptor (INSR, QT00082810) were purchased from Qiagen (Hilden, Germany). ACTB, GAPDH, RPL13A and PPIA were used for normalization according to GeNorm (Vandesompele et al., 2002). The amplified transcripts were quantified using the comparative threshold cycle $(\mathrm{Ct})$ analyzed using the BioRad iCycler iQ program.

\section{Western blot}

Western blotting was used to detect changes in the protein levels of Insulin receptor (IR) $\beta$ subunit in SH-SY5Y cells. To determine total protein amount of each sample, Bradford protein assay was conducted (Sigma-Aldrich, Schorndorf, Germany). Samples $(50 \mu \mathrm{g}$ of total protein, denaturated with dithiothreitol) were separated on 4-12\% Bis-Tris gel and transferred onto nitrocellulose membranes (Life technologies, Darmstadt, Germany). Protein of interest was detected using its specific antibodies: rabbit anti-IR $\beta$ (antibody) (1:250, Santa Cruz, Heidelberg, Germany). Following blocking the membrane for one hour at room temperature (5\% blocking milk in TBS-Tween) and afterwards incubation with primary antibody at $4{ }^{\circ} \mathrm{C}$ overnight, membranes were incubated with HRP conjugated secondary antibody (1:15.000, Sigma-Aldrich, Schorndorf, Germany) for one hour at room temperature. The IR $\beta$ protein immunoreactive bands were detected using the enhanced chemiluminescence (ECL) detection plus system from GE Healthcare (Freiburg, Germany) and quantified using ImageJ software without modifying picture properties (e.g. gain, colour or contrast). For comparison the values of $\beta$-actin, as a house keeping protein, were used. The membranes were stripped to remove the attached antibodies. It was followed by one-hour incubation in 5\% BSA blocking solution at room temperature. The murine $\beta$-actin antibody (1:5000, Santa Cruz, Heidelberg, Germany) was already linked with HRP and was detected and quantified like IR $\beta$ protein.

\section{Enyzme linked immunosorbent assays}

The Invitrogen (Darmstadt, Germany) GSK-3 $\beta$ kit is a solid phase sandwich enzyme linked immunosorbent assay (ELISA) and was used to detect and quantify the level of total GSK-3 $\beta$ protein and of GSK-3 $\beta$ protein phosphorylated at serine residue 9. Samples were prepared according to 
manual. Detected protein amount was normalized with total protein amount of used samples, as detected via Bradford protein assay (Sigma-Aldrich, Schorndorf, Germany).

\section{Enzyme activity}

MAO-B enzyme activity was measured by using amplex red monoamine oxidase assay kit (Life technologies, Darmstadt, Germany). 50 $\mu \mathrm{g}$ of total protein (detected via Bradford protein assay) of homogenized SH-SY5Y cells was diluted in reaction buffer and varying concentrations of soluble and aggregated $\mathrm{A} \beta_{42}$ (see preparation above) $(0.5,1,2.5$ and $10 \mu \mathrm{M})$ were added. After 30 minutes incubation at $37^{\circ} \mathrm{C}, 100 \mu \mathrm{l}$ substrate mix was added and again incubated for 1 hour at $37^{\circ} \mathrm{C}$. The endpoint measurement was done in a fluorescence multi plates meter (Novostar) at an excitation of $542 \mathrm{~nm}$ and an emission of $590 \mathrm{~nm}$.

\section{Statistical analysis}

Statistical analyses of the WB, ELISA and QRT-PCR data were performed using StatView for Windows (SAS Institute Inc., version 5). Statistical tests included analysis of variance (ANOVA) with post-hoc Scheffé Test. Significance was set as $\mathrm{p}<0.05$. For a better comparison of the data, we normalized the results and converted the data into percentages. The control group was set as $100 \%$. The results represent at least 3 repeated experiments with around 4 internal repeats.

\section{Results}

Soluble and aggregated species of $\mathrm{A} \beta_{42}$ were prepared as described above and controlled via electron microscopy (shown in supplementary figure 1). Avoiding neural cell death, we tested a wide range of $\mathrm{A} \beta_{42} \mu \mathrm{M}$ doses $(0-100 \mu \mathrm{M})$ before cell treatment and used just the nontoxic range from $0-10 \mu \mathrm{M}$ for this study. Concentration of over $20 \mu \mathrm{M}$ aggregated $\mathrm{A} \beta_{42}$ showed significant cell toxicity, while for soluble form only a trend to toxicity was observed (supplementary figure 2).

\section{Gene expression}

$B A C E, G S K 3 \alpha, G S K 3 \beta, P I-3 K, I D E, I R S-1$ and INSR were the investigated genes. After gene expression analysis we could detect two genes with significant differences between treated and 
untreated cells. GSK3 $\beta$ was significantly up-regulated after cell treatment with 1 and $2 \mu \mathrm{M}(+362 \%$ $\mathrm{p}<0.05 ;+357 \mathrm{p}<0.05)$ of soluble $A \beta_{42}$ and we could detect a tendency of higher gene expression after treatment with $1,2,5$ and $10 \mu \mathrm{m}$ of the aggregated $A \beta_{42}$ (Table 1). The second gene revealing statistically significant results was the INSR. Treatment with 5 and $10 \mu \mathrm{M}$ of soluble peptides tended to result in a lower INSR gene expression compared to untreated cells while on the other hand, treatments with $1 \mu \mathrm{M}$ of the aggregated peptides tended to result in a higher expression and treatment with 5 and $10 \mu \mathrm{M}$ even led to a significant overexpression of INSR $(+183 \mathrm{p}<0.05 ;+201 \mathrm{p}<0.05$; Table 1). Based on these results we further investigated the protein expression of these two genes in order to examine whether the differences influence gene transcription.

\section{Protein level}

After SH-SY5Y cells were treated with all doses of soluble $A \beta_{42}$, significantly more GSK3 $\beta$ protein levels $(30-45 \%)$ was detectable compared to the control cells $(\mathrm{p}<0.01$, figure $1 \mathrm{a})$, which confirm the gene expression data of $G S K 3 \beta$. Treatments with aggregated peptides did not show any significant effects on GSK3 $\beta$ total protein levels in non of the used doses (figure 1A). Because GSK3 $\beta$ is a kinase enzyme, that when phosphorylated at serine residue 9 becomes inactive, we investigated the phosphorylated form of this protein to affirm whether it is more or less active after $A \beta_{42}$ treatment to the cells. We calculated the ratio between total amount of GSK3 $\beta$ protein and its phosphorylated form, which represents the enzyme activity (figure 1B). Remarkably, not only the total protein amount of GSK3 $\beta$ was statistically significantly increased after treatment with soluble peptides, but there was also a significant detectable enhancement of the enzyme activity under this condition (145\%-231\% more activity in all used dosages compared to untreated cells; $0.01<\mathrm{p}<0.05$; figure $1 \mathrm{~B}$ ). On the other hand the enzyme activity did not alter after treatment with aggregated peptides (figure 1B).

The gene expression data of INSR demonstrated already a tendency for reduced expression after treatment with soluble peptides (table 1), which resulted in significantly decreased total amount of IR $\beta$ after treatment with $0.5,1$ and $2 \mu \mathrm{M}$ of soluble $\mathrm{A} \beta_{42}(50 \%-60 \%$ less total IR $\beta$ protein amount compared to untreated cells, $\mathrm{p}<0.05$; figure 2 ). On the other hand, in the gene expression analysis a significant overexpresion of INSR after treatment with aggregated peptides was observed (table 1), 
which was confirmed only at $1 \mu \mathrm{M}$ aggregated peptide treatment for the total IR $\beta$ protein expression. At $1 \mu \mathrm{M}$ of aggregated $A \beta_{42}$ we could detect $60 \%$ more IR $\beta$ compared to control cells ( $<<0.05$; figure 2).

\section{Enzyme activity}

MAO B enzyme activity was significantly reduced after cell homogenate treatment with $1,2,5$ and $10 \mu \mathrm{M}$ of soluble $\mathrm{A} \beta_{42}$ peptides (18\%-30\% less activity, $\mathrm{p}<0.01$; figure 3 ). In contrast the aggregated peptides enhanced the enzyme activity with significant results at 1,2 and $5 \mu \mathrm{M}$ of aggregated peptide (30\%-40\% more activity compared to control; $\mathrm{p}<0.01$; figure 3 ).

\section{Discussion}

$\mathrm{AD}$ is one of the most common form of dementia in the elderly (Blennow et al., 2006) and although increasing factors are found to be involved in $\mathrm{AD}$, excessive $\mathrm{A} \beta_{42}$ deposition is still considered to play a major role in this disease. $A \beta_{42}$ is derived from the APP by the action of two aspartyl proteases, $\beta$ and $\gamma$-secretases. So accrued $\mathrm{A} \beta_{42}$ molecules tend to aggregate to form soluble oligomers, protofibrils, and $\beta$-amyloid fibrils, which have been suggested to cause neuronal dysfunction in the brains of $\mathrm{AD}$ patients (reviewed in (Ono and Yamada, 2011)). However, it is not well established which $A \beta_{42}$ state is most responsible for $A D$ or why. In this study we verified, which effects $A \beta_{42}$ oligomers and aggregated $A \beta_{42}$ peptides have on gene expression, protein level and enzyme activity of the insulin and APP pathways in vitro. In particular, we have observed a strong influence of the soluble form of $\mathrm{A} \beta_{42}$ peptides on GSK3 $\beta$ gene expression as well as on its protein level and activity. It has been already postulated that GSK3 $\beta$ activity might exert a central role in the development of AD (Hooper et al., 2008). GSK3 $\beta$ activity was implicated in tau phosphorylation, APP processing, $A \beta_{42}$ production and neurodegeneration (Balaraman et al., 2006; Hooper et al., 2008). Our finding of increased GSK3 $\beta$ gene/protein expression and activity points to the fact, that GSK3 $\beta$ might be a crucial element in the $\mathrm{A} \beta_{42}$-triggered molecular cascade leading to potential neurodegeneration. The observed effect of $A \beta_{42}$ oligomers on GSK3 $\beta$ might be mediated by interaction with different receptors, but mainly with the interaction of INSR. It was already shown that $A \beta_{42}$ oligomers interact with neuronal INSR to cause 
impairments of the receptor expression and function (Townsend et al., 2007; Zhao et al., 2009). Normally, activation of INSR leads to the phosphorylation of PI 3-kinase, which leads to an activation of AKT. Once active, AKT enters the cytoplasm where it leads to the phosphorylation and inactivation of GSK3 $\beta$ (Jolivalt et al., 2008). Thus, although normal INSR activity helps to defend against the accumulation of toxic $A \beta_{42}$ oligomers, the INSR themselves are vulnerable to oligomer-initiated dysfunction. The presented data indicate the fact that this relationship has the potential to generate an insidious pathogenic loop. We could observe a significant reduction of INSR gene and protein expression after SH-SY5Y treatment with soluble $A \beta_{42}$ oligomers compared to untreated cells. Consistent with the actual finding reported here, our group could already report that in AD patient less INSR were found especially in the hippocampal region of the brain (Bartl et al., 2012). Not only an impairment of INSR leads to an activation of GSK3 $\beta$ as explained before, also oxidative stress can enhance the activity of this kinase (Hernandez and Avila, 2008). In 2004, Riederer et al. already reviewed the link between oxidative stress and $\mathrm{AD}$, especially regarding the increased MAO-B activity (Riederer et al., 2004). MAO-B is a flavin containing enzyme localized in the outer mitochondrial membrane and is responsible for the oxidative deamination of neurotransmitters (noradrenaline, dopamine and serotonin) and exogenous amines. During its catalytic activity it produces hydrogen peroxide formed in the reaction, which is a possible source for oxidative stress. Highlighting more the possible link between $A \beta_{42}$, GSK3 and MAO-B we analyzed the effect of soluble and aggregated peptides on MAO-B enzyme activity. Interestingly, the soluble oligomers inhibited the enzyme activity significantly, but the aggregated forms of $A \beta_{42}$ peptides, which are more similar to the amyloid plaques within the brain, enhanced the MAO-B activity in a dose dependent manner. Although we could find an inhibition of MAO-B activity after soluble peptide treatment, it cannot be concluded that these oligomers might be neuroprotective. An increased MAO-B activity was found in senile plaques (Saura et al., 1997) and in platelets of AD patients (Gotz et al., 1998), therefore our results of enhanced MAO-B activity following treatment with aggregated while not with soluble $A \beta_{42}$ peptides, might indicate the involvement of the fibrillar structures of $A \beta_{42}$ in the oxidative stress cascade known to play an important role in AD (Grünblatt et al., 2005; Grünblatt et al., 2010). To our knowledge, this is the first report indicating the direct influence of soluble or aggregated 
peptides on MAO-B activity in vitro. Our data affirm that there has to be a neurobiochemical link between MAO-B and $A \beta_{42}$. In conclusion, our results suggest that $A \beta_{42}$ oligomers seem to be more involved in cellular mechanisms linked to $\mathrm{AD}$, except in enhancement of MAO-B activity, than the aggregated $A \beta_{42}$ peptides, which is confirmed with the actual literature. $A D$ seem to involve numerous mechanisms such as amyloid plaque formation, tau hyperphoshprylation, apoptosis, impairment of insulin signaling pathway and oxidative stress, causing neurodegeneration, which means that further investigations are necessary to enlighten the molecular mechanism of AD pathogenesis.

\section{Acknowledgments and Funding}

Funding for this study was partially provided by the "Alzheimer Forschungs Initiative (AFI)", Düsseldorf, Germany; the AFI had no further role in study design; in the collection, analysis and interpretation of data; in the writing of the report; and in the decision to submit the paper for publication. We thank Miryame Hofmann for her excellent technical assistance and also Dr. Zoya Marinova for her great and excellent support. 


\section{References}

Balaraman Y, Limaye AR, Levey AI, Srinivasan S (2006) Glycogen synthase kinase 3beta and Alzheimer's disease: pathophysiological and therapeutic significance. Cell Mol Life Sci 63:1226-1235.

Bartl J, Monoranu CM, Wagner AK, Kolter J, Riederer P, Grunblatt E (2012) Alzheimer's disease and type 2 diabetes: Two diseases, one common link? World J Biol Psychiatry.

Biedler JL, Roffler-Tarlov S, Schachner M, Freedman LS (1978) Multiple neurotransmitter synthesis by human neuroblastoma cell lines and clones. Cancer Res 38:3751-3757.

Blennow K, de Leon MJ, Zetterberg H (2006) Alzheimer's disease. Lancet 368:387-403.

Brunet A, Datta SR, Greenberg ME (2001) Transcription-dependent and -independent control of neuronal survival by the PI3K-Akt signaling pathway. Curr Opin Neurobiol 11:297-305.

Crouch PJ, Harding SM, White AR, Camakaris J, Bush AI, Masters CL (2008) Mechanisms of A beta mediated neurodegeneration in Alzheimer's disease. Int J Biochem Cell Biol 40:181-198.

Dahlgren KN, Manelli AM, Stine WB, Jr., Baker LK, Krafft GA, LaDu MJ (2002) Oligomeric and fibrillar species of amyloid-beta peptides differentially affect neuronal viability. J Biol Chem 277:32046-32053.

De Felice FG, Wu D, Lambert MP, Fernandez SJ, Velasco PT, Lacor PN, Bigio EH, Jerecic J, Acton PJ, Shughrue PJ, Chen-Dodson E, Kinney GG, Klein WL (2008) Alzheimer's disease-type neuronal tau hyperphosphorylation induced by A beta oligomers. Neurobiol Aging 29:13341347.

de la Monte SM, Longato L, Tong M, Wands JR (2009) Insulin resistance and neurodegeneration: roles of obesity, type 2 diabetes mellitus and non-alcoholic steatohepatitis. Curr Opin Investig Drugs 10:1049-1060.

Ghosh AK, Brindisi M, Tang J (2011) Developing beta-secretase inhibitors for treatment of Alzheimer's disease. J Neurochem 120 Suppl 1:71-83.

Glabe CG (2008) Structural classification of toxic amyloid oligomers. J Biol Chem 283:29639-29643. 
Gotz ME, Fischer P, Gsell W, Riederer P, Streifler M, Simanyi M, Muller F, Danielczyk W (1998) Platelet monoamine oxidase B activity in dementia. A 4-year follow-up. Dement Geriatr Cogn Disord 9:74-77.

Grünblatt E, Bartl J, Riederer P (2010) The link between iron, metabolic syndrome, and Alzheimer's disease. J Neural Transm 118:371-379.

Grünblatt E et al. (2005) Oxidative stress related markers in the "VITA" and the centenarian projects. Neurobiol Aging 26:429-438.

Haass C, Selkoe DJ (2007) Soluble protein oligomers in neurodegeneration: lessons from the Alzheimer's amyloid beta-peptide. Nat Rev Mol Cell Biol 8:101-112.

Hernandez F, Avila J (2008) The role of glycogen synthase kinase 3 in the early stages of Alzheimers' disease. FEBS Lett 582:3848-3854.

Hooper C, Killick R, Lovestone S (2008) The GSK3 hypothesis of Alzheimer's disease. J Neurochem 104:1433-1439.

Hoyer S, Muller D, Plaschke K (1994) Desensitization of brain insulin receptor. Effect on glucose/energy and related metabolism. J Neural Transm Suppl 44:259-268.

Jolivalt CG, Lee CA, Beiswenger KK, Smith JL, Orlov M, Torrance MA, Masliah E (2008) Defective insulin signaling pathway and increased glycogen synthase kinase-3 activity in the brain of diabetic mice: parallels with Alzheimer's disease and correction by insulin. J Neurosci Res $86: 3265-3274$

Klyubin I, Betts V, Welzel AT, Blennow K, Zetterberg H, Wallin A, Lemere CA, Cullen WK, Peng Y, Wisniewski T, Selkoe DJ, Anwyl R, Walsh DM, Rowan MJ (2008) Amyloid beta protein dimer-containing human CSF disrupts synaptic plasticity: prevention by systemic passive immunization. J Neurosci 28:4231-4237.

Lesne S, Gabriel C, Nelson DA, White E, Mackenzie ET, Vivien D, Buisson A (2005) Akt-dependent expression of NAIP-1 protects neurons against amyloid-\{beta\} toxicity. J Biol Chem 280:24941-24947. 
Mukherjee A, Song E, Kihiko-Ehmann M, Goodman JP, Jr., Pyrek JS, Estus S, Hersh LB (2000) Insulysin hydrolyzes amyloid beta peptides to products that are neither neurotoxic nor deposit on amyloid plaques. J Neurosci 20:8745-8749.

Munch G, Schinzel R, Loske C, Wong A, Durany N, Li JJ, Vlassara H, Smith MA, Perry G, Riederer P (1998) Alzheimer's disease--synergistic effects of glucose deficit, oxidative stress and advanced glycation endproducts. J Neural Transm 105:439-461.

Ono K, Yamada M (2011) Low-n oligomers as therapeutic targets of Alzheimer's disease. J Neurochem 117:19-28.

Riederer P, Danielczyk W, Grunblatt E (2004) Monoamine oxidase-B inhibition in Alzheimer's disease. Neurotoxicology 25:271-277.

Riederer P, Bartl J, Laux G, Grunblatt E (2010) Diabetes type II: a risk factor for depressionParkinson-Alzheimer? Neurotox Res 19:253-265.

Ross RA, Spengler BA, Biedler JL (1983) Coordinate morphological and biochemical interconversion of human neuroblastoma cells. J Natl Cancer Inst 71:741-747.

Saura J, Andres N, Andrade C, Ojuel J, Eriksson K, Mahy N (1997) Biphasic and region-specific MAO-B response to aging in normal human brain. Neurobiol Aging 18:497-507.

Schindowski K, Belarbi K, Buee L (2008) Neurotrophic factors in Alzheimer's disease: role of axonal transport. Genes Brain Behav 7 Suppl 1:43-56.

Small DH (2004) Mechanisms of synaptic homeostasis in Alzheimer's disease. Curr Alzheimer Res $1: 27-32$.

Townsend M, Mehta T, Selkoe DJ (2007) Soluble Abeta inhibits specific signal transduction cascades common to the insulin receptor pathway. J Biol Chem 282:33305-33312.

Vandesompele J, De Preter K, Pattyn F, Poppe B, Van Roy N, De Paepe A, Speleman F (2002) Accurate normalization of real-time quantitative RT-PCR data by geometric averaging of multiple internal control genes. Genome Biol 3:RESEARCH0034.

Wang DS, Dickson DW, Malter JS (2008) Tissue transglutaminase, protein cross-linking and Alzheimer's disease: review and views. Int J Clin Exp Pathol 1:5-18. 
Zhang Y, Hong Y, Bounhar Y, Blacker M, Roucou X, Tounekti O, Vereker E, Bowers WJ, Federoff HJ, Goodyer CG, LeBlanc A (2003) p75 neurotrophin receptor protects primary cultures of human neurons against extracellular amyloid beta peptide cytotoxicity. J Neurosci 23:73857394.

Zhao WQ, Lacor PN, Chen H, Lambert MP, Quon MJ, Krafft GA, Klein WL (2009) Insulin receptor dysfunction impairs cellular clearance of neurotoxic oligomeric a $\{$ beta $\}$. J Biol Chem 284:18742-18753. 


\section{Figure legends}

Figure 1: Total protein amount of glycogen synthase kinase $3 \beta$ (GSK3ß) and ratio of phosphorylated GSK3ß / total GSK3ß after SH-SY5Y treatment with soluble and aggregated $\mathbf{A \beta}_{42}$ peptides. A Shown is the percentage of the mean values of total amount of the protein measured by a sandwich ELISA . B Shown is the percentage of the mean values of total amount of the protein and of phosphorylated protein amount measured by a sandwich ELISA. Reference value (100\%) is control group with untreated SH-SY5Y cells. For the statistical analysis ANOVA, post-hoc Scheffé with a specified significance level of $\mathrm{p}<0.05$ was used. $*=\mathrm{p}<0.05, * *=\mathrm{p}<0.01$ versus control. The sample size was $n=6-12$.

Figure 2: Total protein amount of insulin receptor (INSR) after SH-SY5Y treatment with soluble and aggregated $\mathbf{A} \boldsymbol{\beta}_{42}$ peptides. Shown is the percentage of the mean values of total amount of the protein measured by western blot . Reference value (100\%) is control group with untreated SH-SY5Y cells. For the statistical analysis ANOVA, post-hoc Scheffé with a specified significance level of $\mathrm{p}$ $<0.05$ was used. $*=\mathrm{p}<0.05, * *=\mathrm{p}<0.01$ versus control. The sample size was $\mathrm{n}=6-12$.

Figure 3: Monoamino oxidase B (MAO-B) activity after SH-SY5Y treatment with soluble and aggregated $\mathbf{A} \boldsymbol{\beta}_{42}$ peptides. Shown is the percentage of the mean values of enzyme activity measured by an amplex red monoamine oxidase assay. Reference value (100\%) is control group with untreated SH-SY5Y cells. For the statistical analysis ANOVA, post-hoc Scheffé with a specified significance level of $\mathrm{p}<0.05$ was used. $*=\mathrm{p}<0.05, * *=\mathrm{p}<0.01$ versus control. The sample size was $\mathrm{n}=20-38$. 
Figure 1: Total protein amount of glycogen synthase kinase $3 \beta$ (GSK3 $\beta)$ and ratio of phosphorylated GSK3 3 / total GSK3 $\beta$ after SH-SY5Y treatment with soluble and aggregated A 342 peptides.
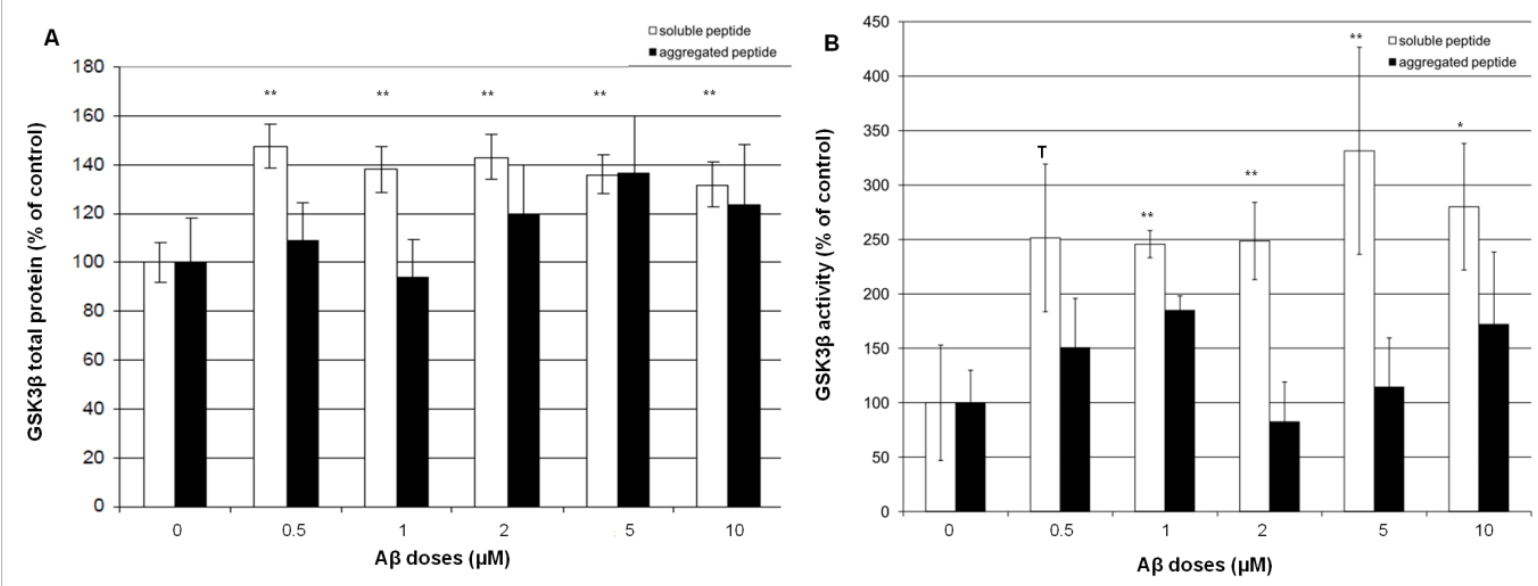

Figure 2: Total protein amount of insulin receptor (INSR) after SH-SY5Y treatment with soluble and aggregated $A \beta 42$ peptides.

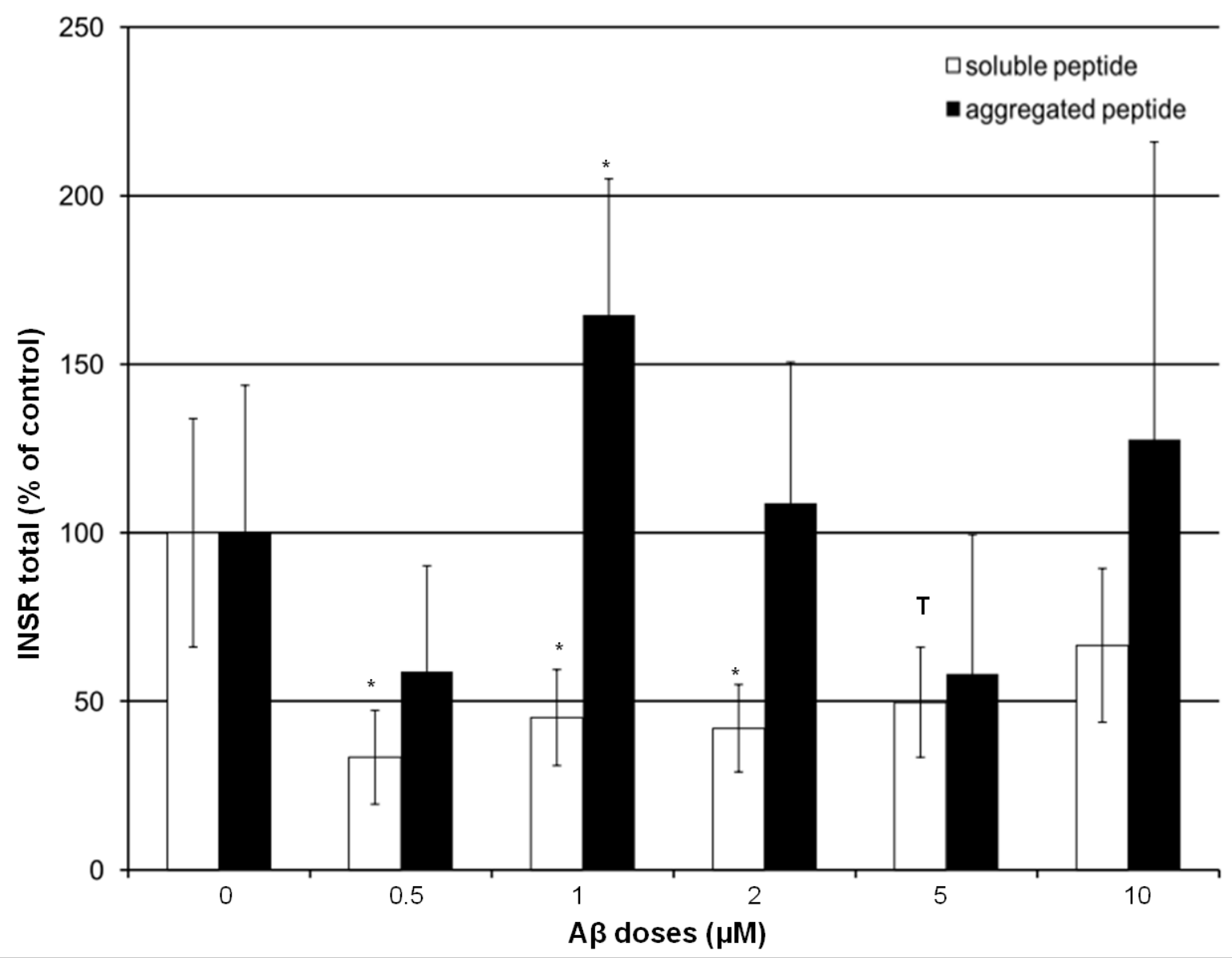


Figure 3: Monoamino oxidase B (MAO-B) activity after SH-SY5Y treatment with soluble and aggregated A 42 peptides.

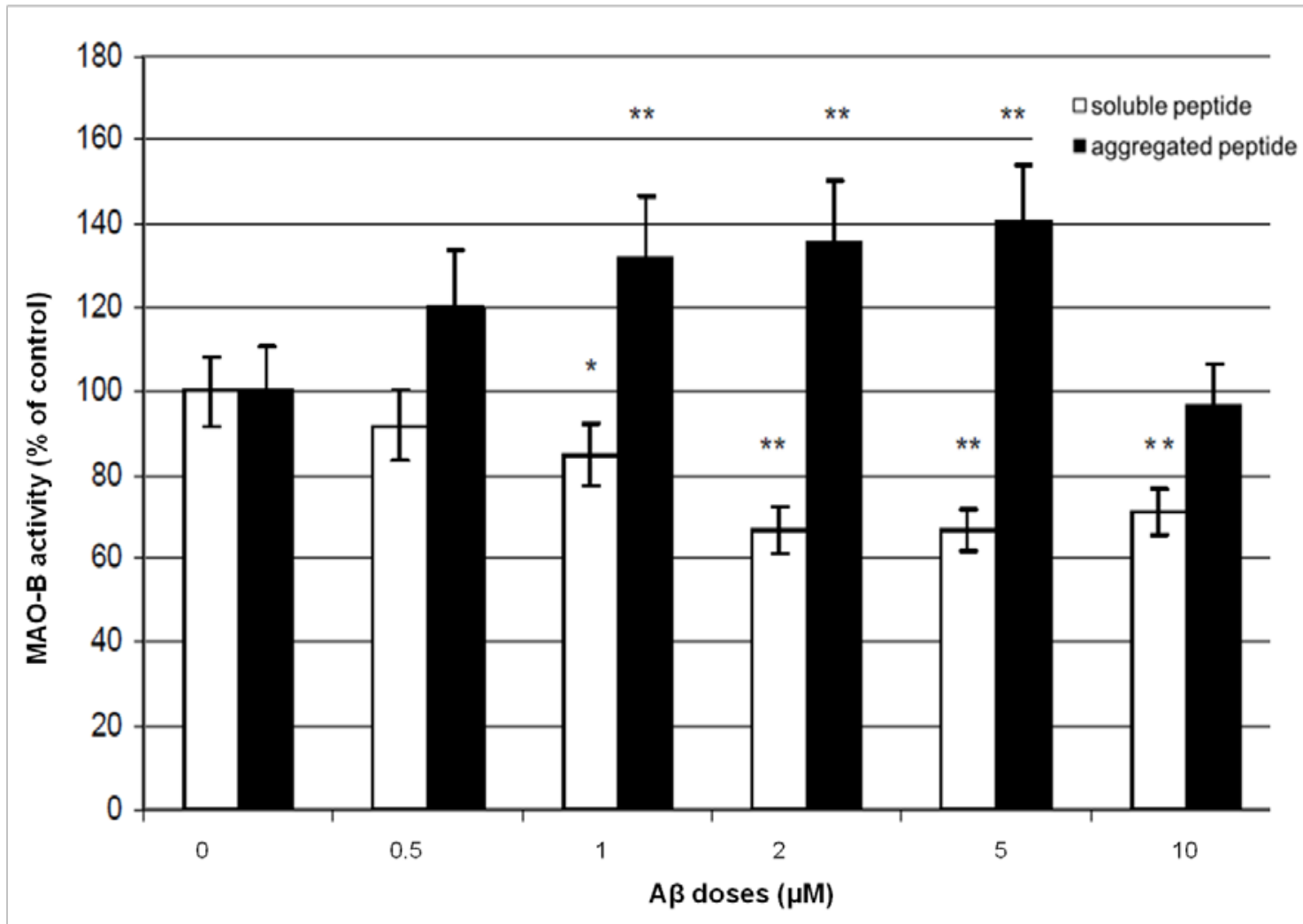

Supplementary figure 1:
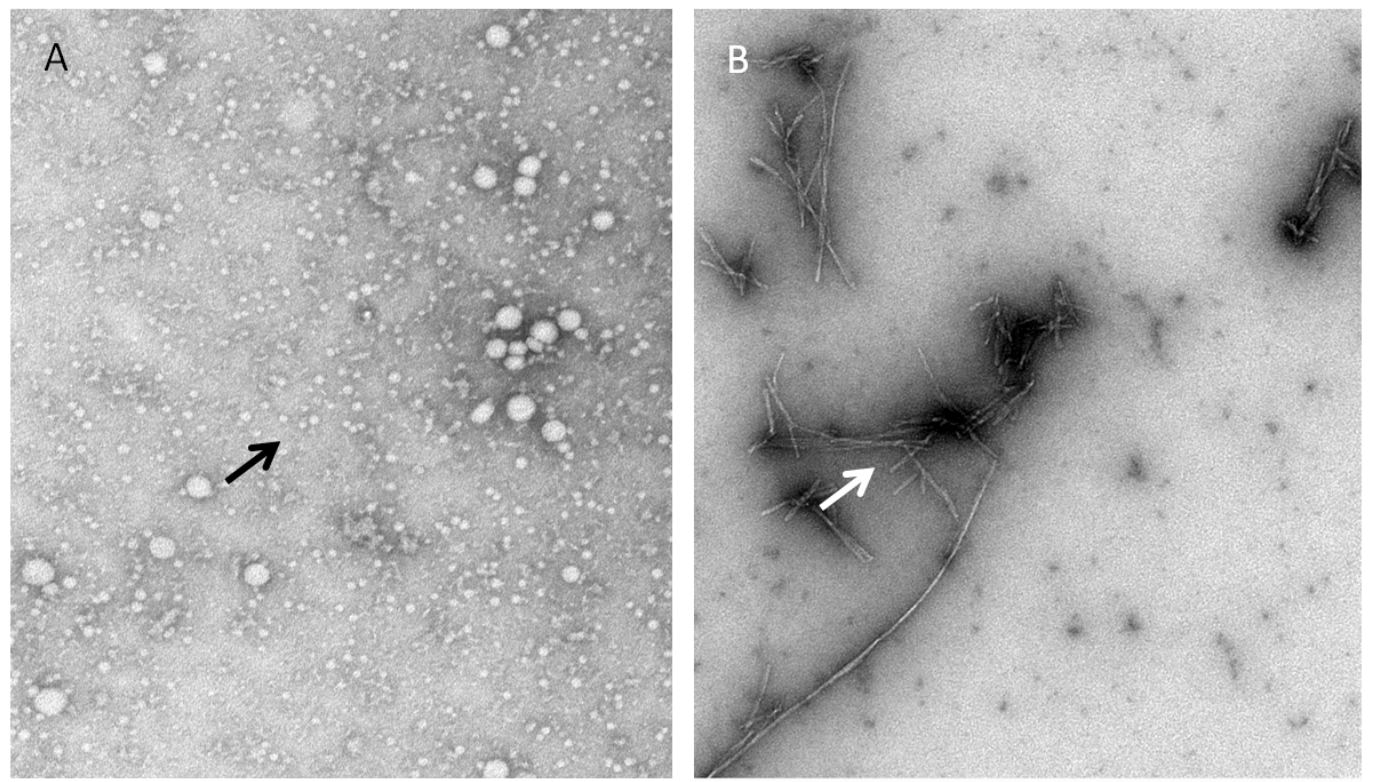

$\underline{200 \mathrm{~nm}}$

Supplementary Figure 1: Electron microscope pictures of soluble and aggregated A $\beta_{42}$ peptides. $5 \mu 1$ of samples were spotted on a glow discharged, carbon-coated grid and incubated for $5 \mathrm{~min}$, washed with distilled water, fixed with $2.5 \%$ glutaraldehyde, stained with a $1 \%(\mathrm{w} / \mathrm{v})$ aqueous uranyl acetate solution, and examined using a transmission electron microscope 20.000 fold magnification. A. arrow points to soluble $A \beta_{42}$ peptides; $B$. arrow points to aggregated $A \beta_{42}$ peptides. 
Supplementary figure 2:

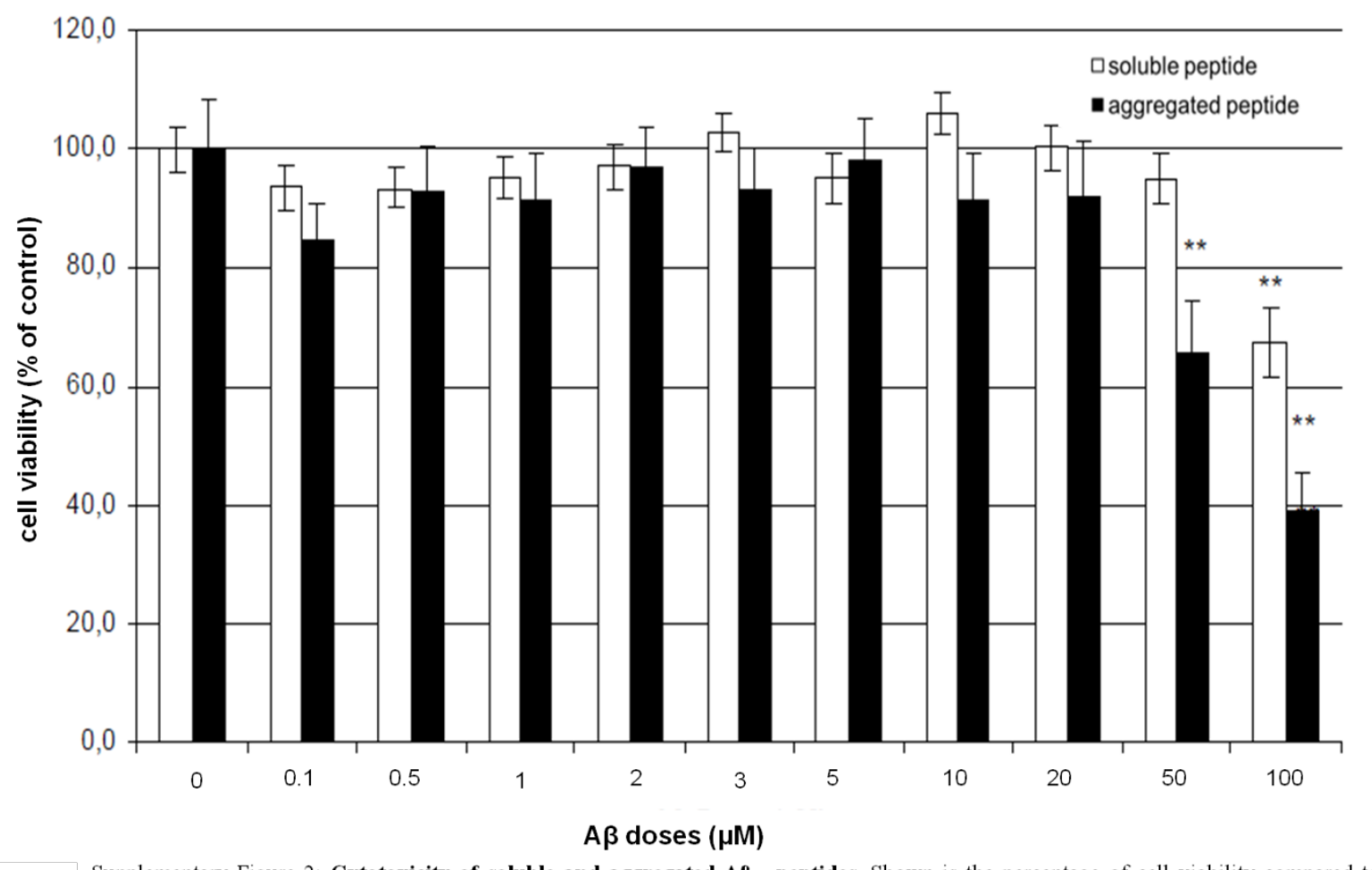

Supplementary Figure 2: Cytotoxicity of soluble and aggregated $\mathbf{A} \boldsymbol{\beta}_{42}$ peptides. Shown is the percentage of cell viability compared to control group of SH-SY5Y after $48 \mathrm{~h}$ of treatment with soluble and aggregated $\mathrm{A} \beta_{42}$ peptides. The number of viable cells is calculated from the subtraction of the dead cells of the total cell number. Statistical analysis of cytotoxicity was performed using ANOVA, post-hoc Scheffe; $* *=p<0.01$ versus control. The sample size was $n=13-22$. 